\title{
Click Chemistry Enabling Covalent and Non-Covalent Modifications of Graphene with (Poly)saccharides
}

\author{
$\mathrm{Hu} \mathrm{Li}^{1,2}$ (D) and Raffaello Papadakis ${ }^{3,4, *(\mathbb{D})}$ \\ 1 Shandong Technology Centre of Nanodevices and Integration, School of Microelectronics, \\ Shandong University, Jinan 250101, China; lihu.goodluck@gmail.com \\ 2 Department of Materials Science and Engineering, Uppsala University, 75121 Uppsala, Sweden \\ 3 TdB Labs AB, Uppsala Business Park, 75450 Uppsala, Sweden \\ 4 Department of Chemistry, Uppsala University, 75120 Uppsala, Sweden \\ * Correspondence: rafpapadakis@gmail.com; Tel.: +46-7283-685-95
}

check for

updates

Citation: Li, H.; Papadakis, R. Click Chemistry Enabling Covalent and Non-Covalent Modifications of Graphene with (Poly)saccharides. Polymers 2021, 13, 142. https:// doi.org/10.3390/polym13010142

Received: 8 November 2020 Accepted: 28 December 2020 Published: 31 December 2020

Publisher's Note: MDPI stays neutral with regard to jurisdictional clai$\mathrm{ms}$ in published maps and institutional affiliations.

Copyright: (C) 2020 by the authors. Licensee MDPI, Basel, Switzerland. This article is an open access article distributed under the terms and conditions of the Creative Commons Attribution (CC BY) license (https:// creativecommons.org/licenses/by/ $4.0 /)$.

\begin{abstract}
Graphene is a material with outstanding properties and numerous potential applications in a wide range of research and technology areas, spanning from electronics, energy materials, sensors, and actuators to life-science and many more. However, the insolubility and poor dispersibility of graphene are two major problems hampering its use in certain applications. Tethering mono-, di-, or even poly-saccharides on graphene through click-chemistry is gaining more and more attention as a key modification approach leading to new graphene-based materials (GBM) with improved hydrophilicity and substantial dispersibility in polar solvents, e.g., water. The attachment of (poly)saccharides on graphene further renders the final GBMs biocompatible and could open new routes to novel biomedical and environmental applications. In this review, recent modifications of graphene and other carbon rich materials (CRMs) through click chemistry are reviewed.
\end{abstract}

Keywords: graphene; (poly)saccharides; click chemistry; hydrophilicity; click grafting; CRMs

\section{Introduction}

Graphene holds great potentials in numerous applications ranging from electronics and optoelectronics to mechanical reinforcement technologies, energy materials, sensors and actuators and many more. Properties of these materials such as aqueous stability and biocompatibility are essential, especially in the arena of biological and medical applications $[1,2]$. Yet, graphene is hydrophobic and irreversibly forms agglomerates or tends to restack when in water due to the strong $\pi-\pi$ stacking interlayer interactions. This causes significant difficulties in application areas such as biomedicine and biomaterials-involving technologies [3]. To address this challenge, various functionalization approaches have been developed to enhance the dispersibility of graphene in water and other polar solvents [4]. Typically, functionalization or structure modifications can lead to new graphene-based materials with enhanced properties [5-7].

For instance, graphene oxide (GO) which can be obtained by chemical oxidation of graphene exhibits excellent dispersibility in various solvents [8]. Various types of functionalization, such as (hydro)silylation [9] or hydroxypropylation [10], of graphene or differential functionalization of carboxyl moieties on GO [11] and even pure geometry modification to form graphene nanoscrolls [12] have been reported as potential amendments tentatively leading to enhanced performance during dispersion. Nonetheless, many of these approaches involve reagents which are considered as non-biocompatible or toxic.

Covalent and non-covalent functionalization of graphene with mono-, di- or even polysaccharides (PSs) has recently attracted a great deal of interest owing to the exceptionally nontoxic, hydrophilic, biocompatible, and biodegradable nature, of saccharides $[13,14]$. The resulting graphene derivatives show great potentials in the areas of biocomposites, biomedicine, and biosensors $[15,16]$. For instance, Liu et al. reported a facile and rapid green 
strategy to fabricate glucose functionalized graphene that is employed as a cooperative nanotemplate for both photothermal therapy and drug loading [17]. Han et al. develop a methodology to achieve graphene functionalization of pyrene-maltose as a Concavalin A biosensor, which demonstrates superior selectivity and nanomolar sensitivity [18]. It comes as no surprise that currently there is a rapidly increasing number of publications dealing with (poly)saccharide modifications of GBMs [19-22]. Yet, in order to achieve these modifications, facile, green and biorthogonal synthetic methods are required. Moreover, it is required that these synthetic methods lead to few or even no byproducts and result in high degrees of substitution. A synthetic approach fulfilling the above requirements is "click chemistry". Up to date various click methodologies/strategies for graphene have been reported [23-26]. When it comes to (poly)saccharide modifications of graphene, there is a range of research works conducted in the last ten years which to the best of the authors' knowledge have not been reviewed so-far. The aim of this review paper is to categorize the different click strategies that can be employed in graphene (poly)saccharide modifications. This review paper also extends to modifications of relevant carbon rich materials and compounds (CRMs), i.e., materials and compounds with a $\mathrm{C} / \mathrm{H}$ ratio higher than $1 / 1$ [27]. Important examples of CRMs are carbon nanotubes (CNTs) and polycyclic aromatic hydrocarbons (PAHs) [27], both discussed herein.

\section{Functionalization Methodologies Involving Click Chemistry}

There are various routes allowing for (poly)saccharide functionalization of graphene. One of the most prominent functionalization approaches of that type which to the best of the authors' knowledge has not been reviewed so far, is the click chemistry approach [28]. The term click chemistry covers a range of chemical reactions all of which exhibit some important common characteristics, namely high modularity, insensitivity towards oxygen and water as well as towards the choice of solvent, high to even quantitative chemical yields, no byproducts as well as a large gain of thermodynamic enthalpy $(\Delta \mathrm{H}(>20 \mathrm{kcal} / \mathrm{mol}))$. These characteristics/requirements are met by various reactions the most prominent being the renowned copper(I)-catalyzed azide-alkyne cycloaddition (also known as CuAAC) [29]. The number of the annually published research works in the field of click chemistry is steadily higher than 1000 reflecting the high utility of click chemistry methodologies (see Figure 1). Modifications of sugars via click chemistry are common and have been in use since several years. This explains why there is a nearly stable annual number of publications in this research field during the last decade (Figure 1). Interestingly, there is an increasing number of publications pertaining to click chemistry and graphene (Figure 1) which reflects the high suitability of click chemistry for the modification of graphene and its derivatives.

The various approaches leading to polysaccharide-modified graphene can be categorized into three types (see Figure 2). In the first approach (Figure 2a), covalent graphene functionalization is achieved only on the basal plane of graphene. This typically requires a pre-modification of the desired functionality to be attached, e.g., alkyne or azide modification when CuAAC is applied as well as of the of basal plane carbon atoms of graphene (azide or alkyne modification respectively). This graphene premodification can often be a nucleophilic attack leading to epoxy ring opening in $\mathrm{GO}$ or a substitution of an $-\mathrm{OH}$ group on the basal plane of GO [30]. The second approach (Figure 2b) provides graphene functionalization at the edges and it requires similar premodifications as in approach a), the only difference being that graphene is pre-modified only at its edge carbon atoms (often through a reaction of the $\mathrm{GO}$ edge - $\mathrm{COOH}$ groups) [30]. The third approach (Figure 2c) leads to non-covalently functionalized graphene through stabilization of molecules which can be attached on the surface of graphene though weak interactions (typically through $\pi-\pi$ interactions). 


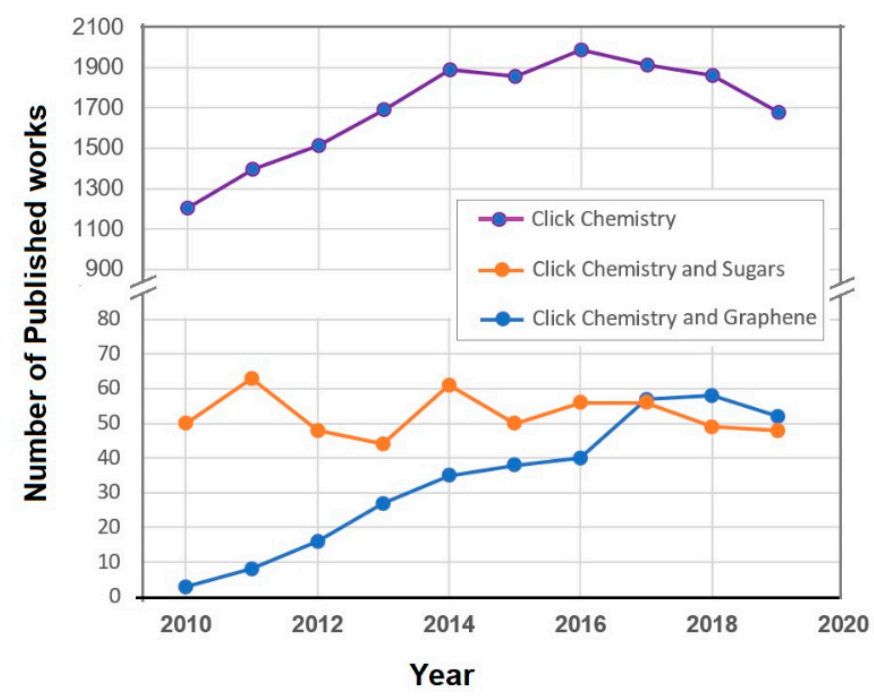

Figure 1. Plots depicting the number of published works in three research areas relevant to this review paper for the last ten years. Keywords used: "Click Chemistry", "Click Chemistry" and "Sugars" and "Click Chemistry" and "Graphene". Searched through: Web of Science. Search performed on 26 November 2020.
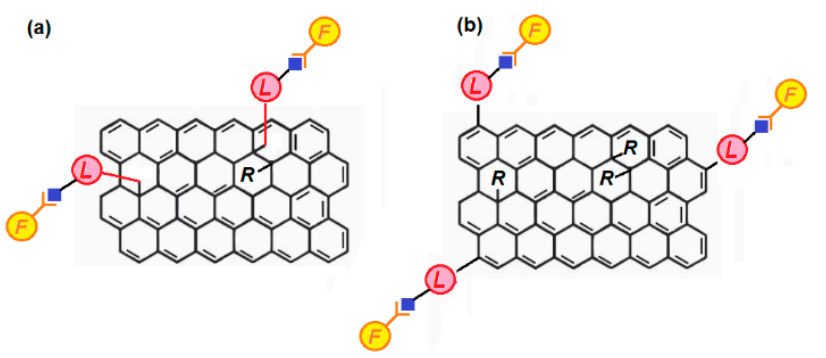

(c)

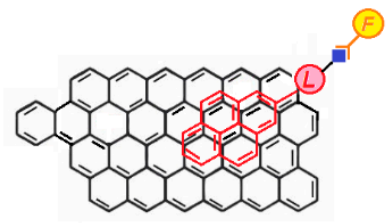

Figure 2. Covalent functionalization of graphene enabled through click chemistry in the basal plane (a) and at the edges (b). Non-covalent modification of graphene through $\pi$ - $\pi$ stacking interactions of a functionalized pyrene through click chemistry (c) (L corresponds to a linker, $\mathbf{F}$ to a functional group attached through a click approach. $L$ and $\bullet$ correspond to the two complementary chemical parts prone to undergo a click-coupling; $\mathbf{R}$ random graphene substituent).

These molecules can bear a functionality which is desired for a specific application. The role of click chemistry here is to enable covalent attachment of this functionality on a molecule which shows proven affinity to the $\pi$-conjugated surface of graphene, e.g., a polycyclic aromatic hydrocarbon (PAH) [31].

Various complementary methods to click chemistry are known (see Figure 3). In many occasions, functionalization of graphene or GO is required prior to click chemistry. This is typically achieved through functionalization of GO edge-lying groups such as $-\mathrm{COOH}$ or -OH groups, or basal plane groups (mostly epoxide groups). For instance, in a CuAAC methodology one should first alkyne- or azide- functionalize GO, then azide- or alkynefunctionalize the target substrate (e.g., a polysaccharide) respectively to finally link the two parts via a $\mathrm{Cu}(\mathrm{I})$ catalyzed reaction. The aforementioned methodology is followed in many of the examples presented in this review work.

Direct functionalization of graphene through click chemistry can also be achieved via Diels Alder reactions or other types of cycloadditions (see Figure 3). Some relevant examples to this methodology are also included in Section 3.1. 

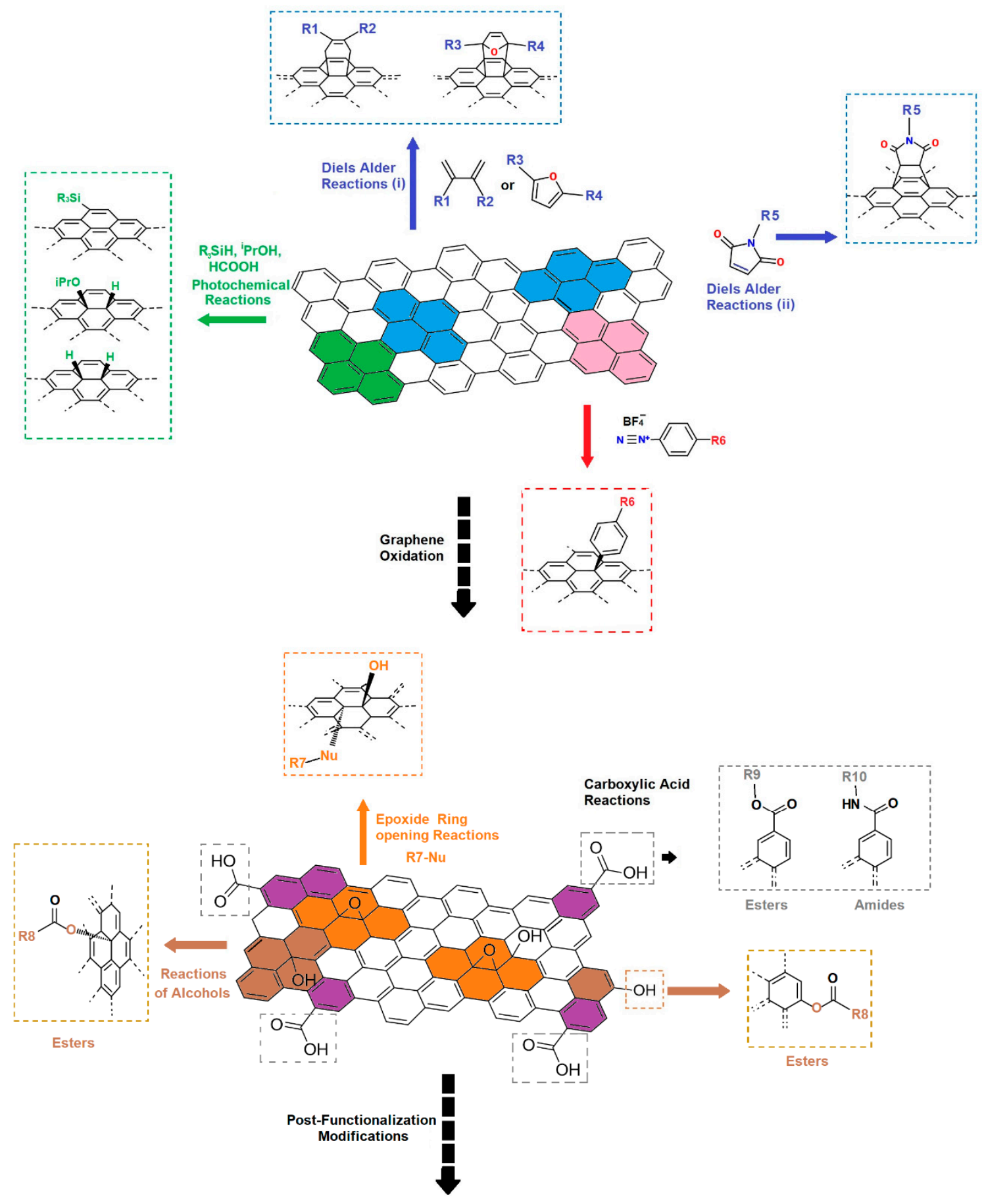

Figure 3. Various functionalization reactions of graphene (upper part) and GO (lower part) relevant/complementary to click chemistry. (R1 to R10 represent various substituents; Nu corresponds to a nucleophile).

\section{Covalent Conjugation of (Poly)saccharides to Graphene}

\subsection{Poly- and Oligo-Saccharides}

In recent years functionalization of graphene with chitosan (Structure 1 in Figure 4) has become very attractive since materials comprising these two components would exhibit a mix of the beneficial properties of graphene along with the biocompatibility, low toxicity, and biodegradability of chitosan [32]. Chitosan-based materials have attracted much interest due to their suitability for various industrial, biomedical and research applications spanning from waste water treatment [33] and oil/seawater separation systems [34] to 
tissue engineering [35] and carbon dioxide capturing aerogels [36]. One of the first attempts to graft chitosan on graphene came as early as 2013 by Ryu et al. and a click chemistry approach was employed for the coupling of this polysaccharide to GO [37].

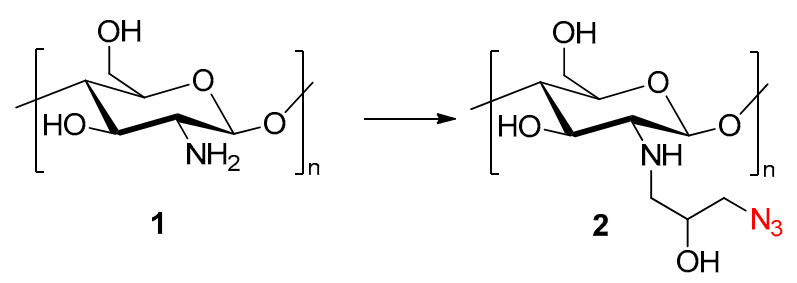

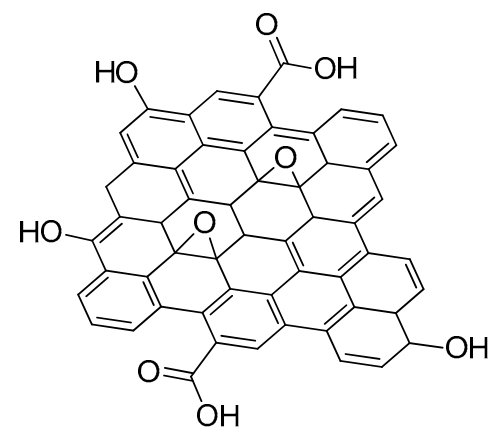

3

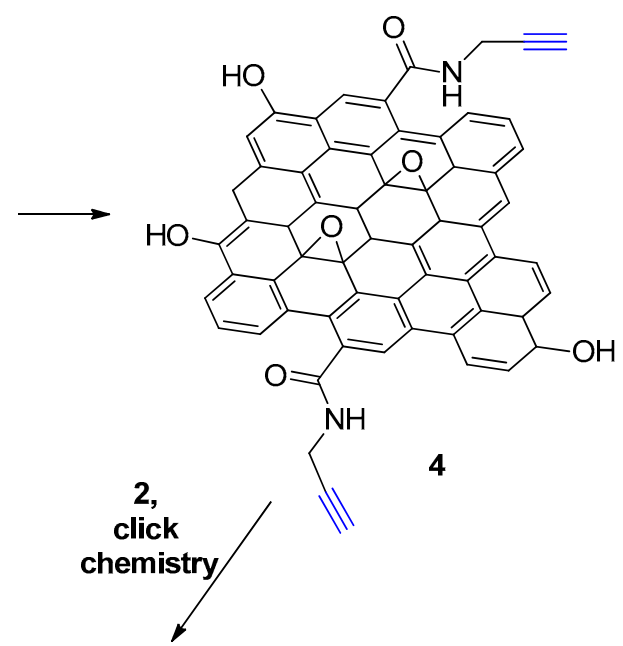

而

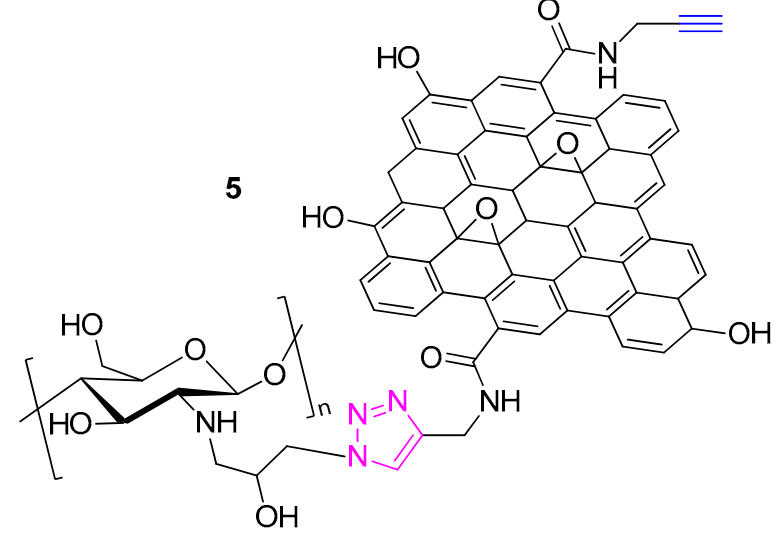

Figure 4. Synthetic route followed by Ryu et al. [37] for the preparation of chitosan functionalized graphene (5).

In a first step, the azido moiety was introduced via a reaction of the chitosan with azido-epichlorhydrin (N-functionalization of chitosan) leading to polymer 2. GO (3) was then treated with propargylamine (in the presence of dicyclohexylcarbodiimide) to afford transformation of the edge carboxy groups of GO to propargyl amide groups (4). The two counterparts 2 and $\mathbf{4}$ were clicked together via a $\mathrm{Cu}(\mathrm{I})$-catalyzed Huisgen 1,3-dipolar cycloaddition and chitosan-functionalized graphene oxide (5) was finally isolated. The described methodology enables selective functionalization of GO at its edges since the carboxy groups (lying at the edges of GO) were selectively alkyne-modified prior to the click reaction with the azide-modified chitosan.

The opposite click strategy was followed by Kabiri and Namazi in 2014 [38], to achieve a nanosized cellulose functionalized graphene. According to this approach GO 
was azidated whereas the polysaccharide (cellulose) was alkyne-modified (opposite to the strategy followed by Ryu et al. [37]). The reaction route, briefly described in Figure 5, leads to polysaccharide functionalization at the sheet edges of GO. In a final step reduction of GO using hydrazine leading to a final cellulose-graphene (10) derivative is achieved. The relevance of this synthetic strategy is high as it clearly proves the orthogonality of click chemistry [39] allowing for a post-functionalization reduction of GO without leading to an inferior degree of polysaccharide substitution. Indeed, the final functionalized material is characterized by a $23 \%$ degree of substitution by mass. It is also noteworthy that the described methodology leads to an increased hydrophilicity and dispersibility in aqueous media of the final graphene-based material and this is one of the primary reasons why (poly)saccharide graphene modifications are desired.
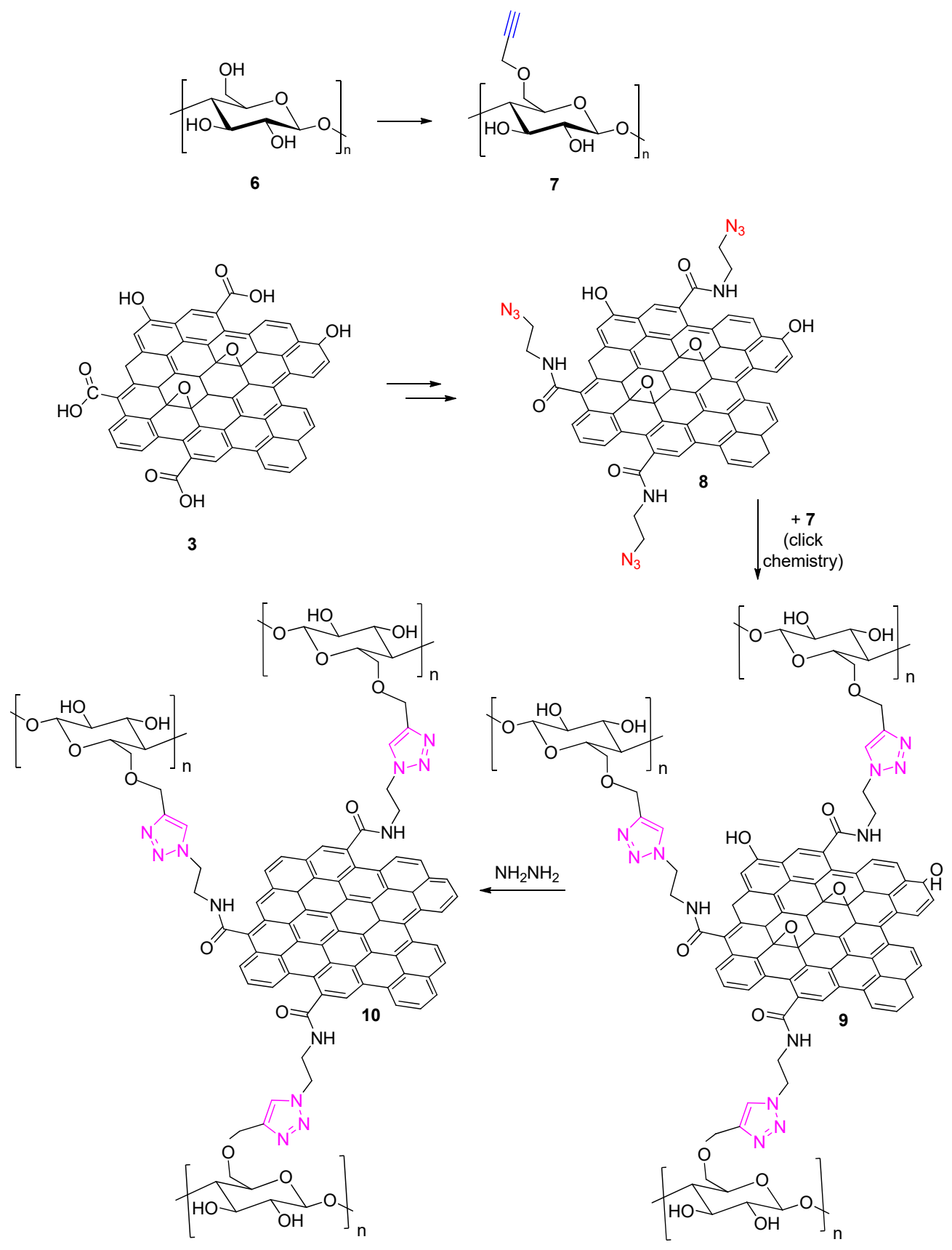

Figure 5. Synthetic strategy employed by Kabiri and Namazi [38] for the preparation of cellulose-modified graphene. 
More recently (in 2019), click-coupling of $\beta$-cyclodextrin ( $\beta$-CD) on GO was reported by Ye et al. [40]. CDs are cyclic oligosaccharides with numerous applications in environmental [41], and supramolecular chemistry [42-44]. They exhibit a high solubility in water yet, they retain a hydrophobic cavity interior, thereby they can efficiently trap hydrophobic molecules in aqueous solutions. This property renders $C D$ s valuable candidates for nanocarrier systems based on carbon rich materials (CRMs), such as graphene or GO [40]. In the work by Ye et al., clicking a $\beta$-CD on graphene was made possible through an interesting approach involving click chemistry.

In a first step $\beta-C D$ was partly oxidized to ox- $\beta-C D$ with use of sodium periodate [45] (Figure 6, ox- $\beta$-CD: 11). In another step, folic acid-functonalized with a maleimide unit was reacted with ox- $\beta-C D$ to afford through condensation between an aldehyde unit of ox- $\beta-C D$ and the folic acid amino group, scaffold (12). Finally, 12 was clicked on GO via a Diels-Alder click reaction to yield the GBM 13 (Figure 6) [46]. Notably, maleimide is a well-known dienophile which has been involved in Diels-Alder click reactions with a wide range of substrates, spanning from small polycyclic aromatic hydrocarbons (e.g., anthracene) [47] to CRMs, including CNTs and GBMs [48]. Remarkably, CRMs can act both as dienes and as dienophiles in Diels-Alder click reactions [49].
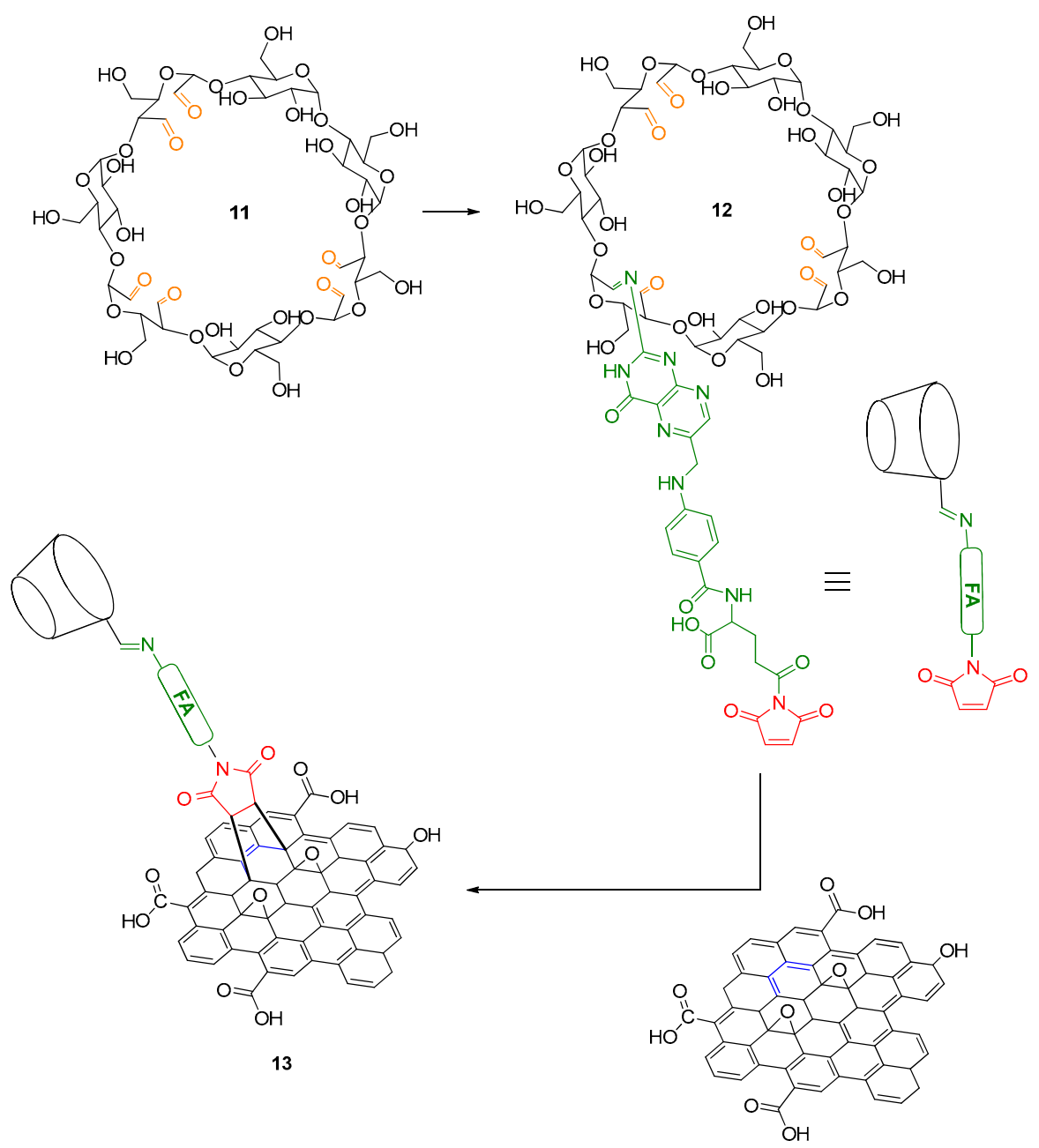

Figure 6. Synthesis of click-coupled $\beta$-CD on graphene by Ye et al. [40].

An alternative method allowing for the functionalization of graphene with a polysaccharide was recently (2020) described by Huang et al. [50]. In this approach, chitosan (1) after N-propargylation (14) was reacted to para-nitrobenzyl azide (15) by employing CuAAC click chemistry (Figure 7). The chitosan scaffold was further modified to the 
corresponding benzene diazonium tetrafluoroborate before it was finally coupled to GO to yield a chitosan-modified graphene (19). This approach is useful when a CuAAC click chemistry on a GBM is not directly feasible. The reactivity of aryldiazonium salts towards graphene [51-53] is well-known and it enables the final fixation of the pre-clicked polysaccharide scaffold. In terms of properties, it was found that the graphene-based final material exhibited an improved antimicrobial activity when compared to chitosan itself [50].

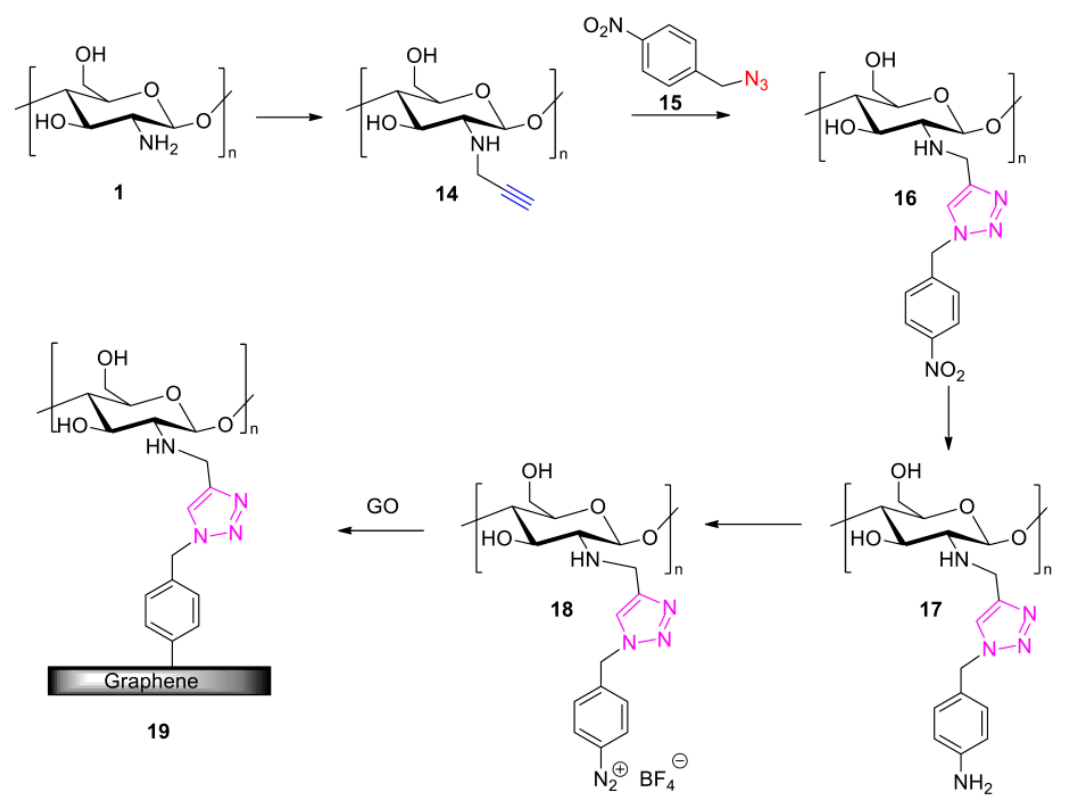

Figure 7. CuAAC Click assisted synthesis of chitosan-modified graphene by Huang et al. [50].

In this paragraph, recent examples of click chemistry-enabled modifications of graphene with oligo- and poly-saccharides were reviewed. Different approaches allowing for the functionalization of graphene either at its edges or at the basal plane were presented. Huisgen 1,3-dipolar cycloaddition reactions as well as Diels Alder click reactions were employed in most of the cases. In the next paragraph focus is placed on mono- and di- saccharides.

\subsection{Mono and Di-Saccharides}

One of the earliest attempts to functionalize graphene with small sugars (mono- or di-saccharides) using a click chemistry methodology was that by Namvari and Namazi [54]. In a first step, graphene oxide (GO) was azide-modified through simple reactions, and then it was functionalized with a variety of mono- and di-saccharides via $\mathrm{Cu}(\mathrm{I})$ catalyzed Huisgen 1,3-dipolar cycloaddition reactions [29,55]. The saccharides (galactose, maltose, glucose and mannose) were alkyne-modified in a separate step. The resulting family of these sugar-graphene conjugates which the authors called "sweet graphene" [54] exhibited interesting properties such as very good dispersibility in water as well as high stability. What was shown is that the same type of functionalization can be achieved both at the basal plane and at the edges of graphene by modifying the "azidation" step. By reacting GO with $\mathrm{NaN}_{3}$, click is directed towards the epoxy groups (basal plane). On the other hand, by first reacting GO with 1,3-diazidopropan-2-ol (after activating the terminal carboxylic acid units (edges) through reaction with $\mathrm{SOCl}_{2}$ ), the click reactions with the alkyne-sugars finally yield an edge-modified GO. This approach indicates the versatility of the clickmethodology enabling two functionalization modes (basal plain or edges functionalization) while retaining the same substrate.

The same research group later on reported on an extension of their first work on "sweet-graphene" in which they employed two different CuAAC click-reactions in order to achieve basal plane and edges functionalization of GO with glucose. (see Figure 8) [56]. In a similar fashion as before, this required the pre-alkyne modification of $\mathrm{GO}$ at the edge 
- $\mathrm{COOH}$ entities or at the -OH basal plane entities (Figure 8). Coupling reactions of each of these pre-modified GOs with azido-ethylene glucose (structure 22 Figure 8 ) in the presence of $\mathrm{CuSO}_{4}$ and ascorbate (reducing agent) resulted in glucose-functionalized GOs. What is interesting especially with the basal plane modification is that a dendrimer-like structure is achieved since the GO precursor involved entities with three alkyne groups each. This allowed coupling to three units of glucose through the applied CuAAC approach. The resulting GBM is characterized by enhanced hydrophilicity [56]. The hydrophilic graphene nanosheets were further combined to $\mathrm{Fe}_{3} \mathrm{O}_{4}$ nanoparticles and the superparamagnetic properties of the final materials were analyzed [56]. The efficient and stable deposition of the $\mathrm{Fe}_{3} \mathrm{O}_{4}$ nanoparticles is clearly associated to the hydrophilicity of the synthesized materials through click chemistry.

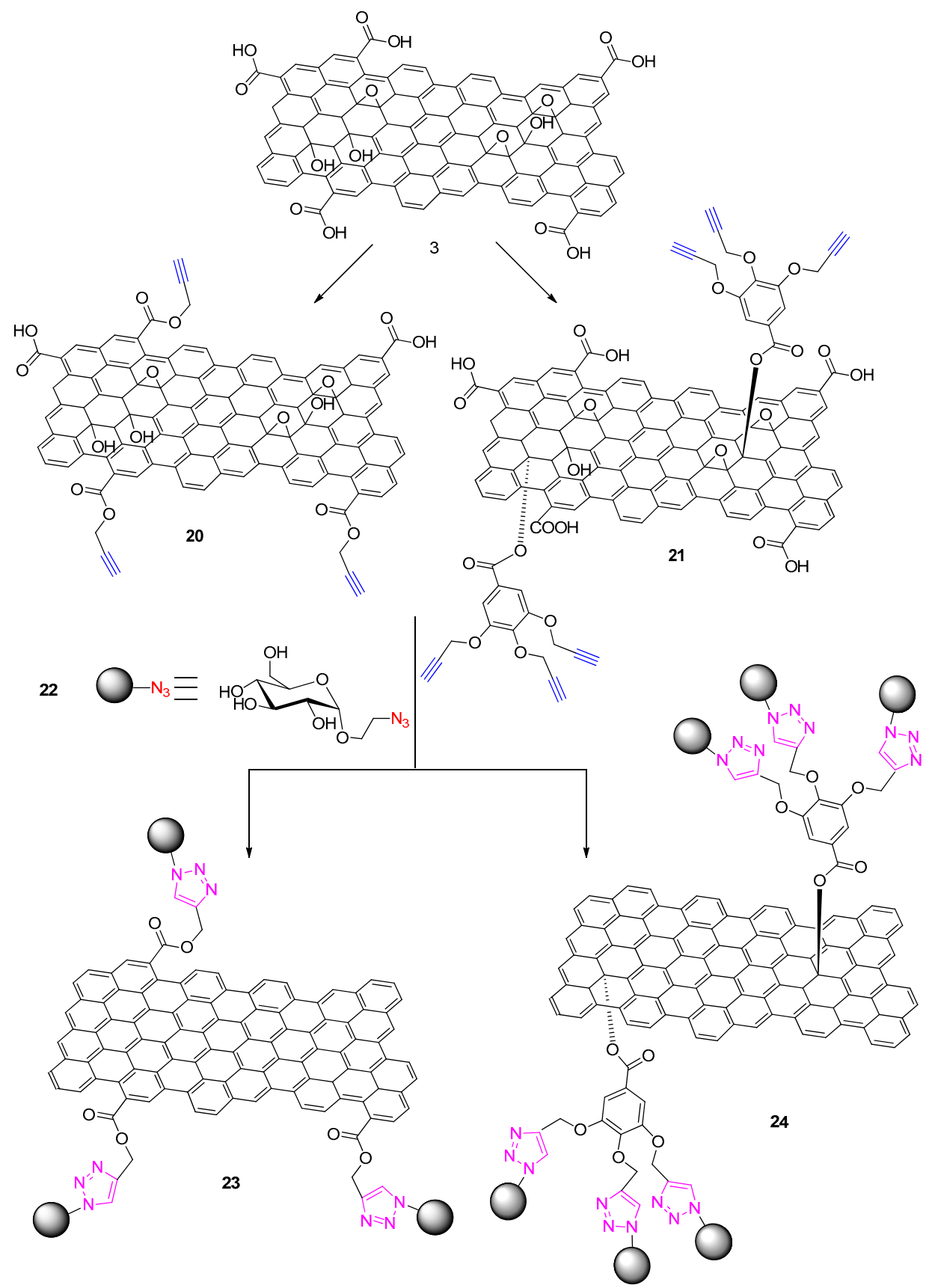

Figure 8. The two click-assisted synthetic routes to graphene glucose functionalization at the edges (product 23) and at the basal plane (24) by Namvari and Namazi [56]. 
In this paragraph substitution reactions of graphene with mono- and di- saccharides were reviewed and the required preparations of the graphene and saccharide precursors were discussed. $\mathrm{A} \mathrm{Cu}(\mathrm{I})$ catalyzed Huisgen 1,3-dipolar cycloaddition was identified as the click method mostly used for this type of graphene covalent modifications. This is presumably because of the ample existing knowledge on the azide- or alkyne-modifications of mono- and di-saccharides [28]. In the next paragraph, click-assisted non-covalent graphene modifications are discussed.

\section{Non-Covalent Conjugation of (Poly)saccharides to Graphene}

Another way to modify graphene is through the so-called non-covalent functionalization approach. In this case, the functionalities are not bound to graphene by means of a covalent bond but instead they are typically bound to a compound which can stay on the surface of graphene by means of relatively weak interactions, e.g., through $\pi-\pi$ interactions between a PAH and graphene. This strategy is often preferred when it is desired that the electrical and electronic properties of graphene are retained after functionalization and this can be ensured by means of methodologies which retain intact the fully $\pi$-conjugated honeycomb structure of graphene [31,57]. In this section, non-covalent approaches allowing for saccharide functionalization of graphene are reviewed.

Kaminska et al. reported in 2012 on a click-chemistry assisted method to noncovalently functionalize GO [58]. By using an azido-tetrathiafulvalene (az-TTF: 25) scaffold which they initially non-covalently functionalized GO and in one step they achieved reduction of GO to rGO merely using sonication. The reducing capacity of the az-TTF is such that allowed for the GO to rGO reduction. The result is a GBM involving non-covalent az-TTF-functionalization. Moving a step further it was possible to apply a CuAAC chemistry to tether a monosaccharide unit (mannose) which was pre-alkyne modified. The final material was thus a modified graphene involving a monosaccharide prepared in two steps (structure 28). What is even more interesting is that the mannose-TTF units can reversibly be detached form the graphene surface merely by applying the tetracationic cyclophane cyclobis(paraquat-p-phenylene): 29 which efficiently binds mannose-TTF. The process was nicely monitored by means of Atomic Force Microscopy (AFM) (see Figure 9C).

A
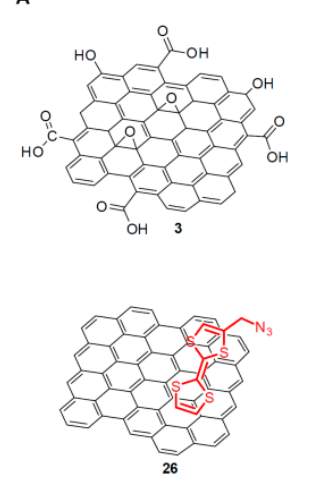

B

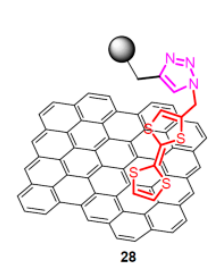

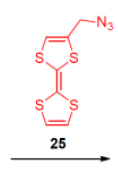

25
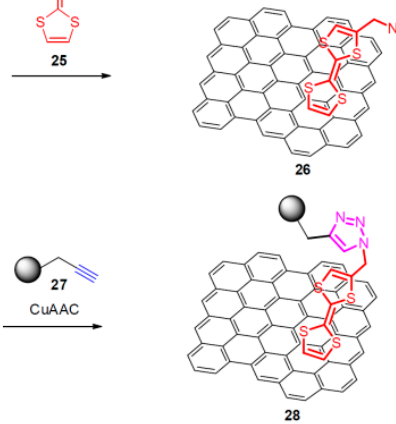

c
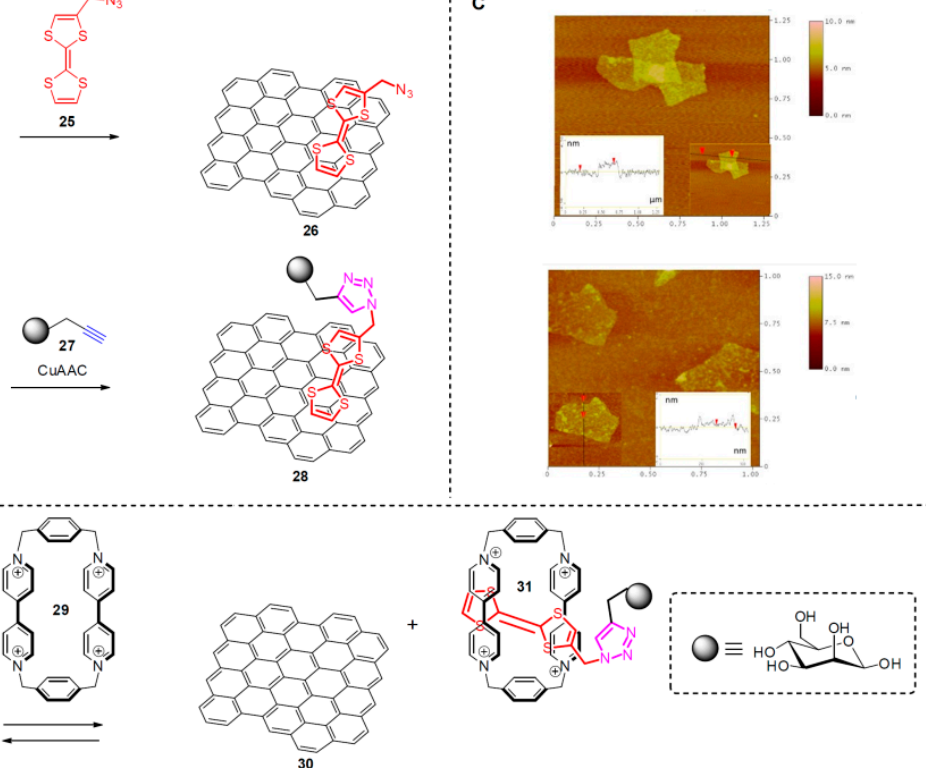

Figure 9. (A) Non-covalent functionalization of r-GO with TTF-mannose (B) Reversible removal of mannose-TTF from graphene and; inset depict the structure of the monosaccharide mannose (C) AFM images before (top) and after (bottom) immersing the r-GO-TTF-mannose in a solution of cyclobis(paraquat-p-phenylene). The AFM images are reproduced with permission from Kaminska et al. [58]. 
Subsequently, Zhang et al. [59] reported on graphene modified materials useful as fluorogenic sensors for the recognition of specific intercellular glycoprotein receptor interactions. The authors characterized this GBM as "2D glycosheet". Click chemistry enabled the preparation of these materials (see Figure 10). The synthetic approach followed, involved two different $\mathrm{N}$-acetyl hexosamine rhodamine $\mathrm{B}$ derivatives (compounds $\mathbf{3 2}$ and 33) varying on the type of monosaccharide employed ( $\mathrm{N}$-acetyl galactosamine in case of $\mathbf{3 2}$ and N-acetyl glucosamine in case of 33). Alkyne-modified rhodamine B was attached to each azido-monosaccharide through a $\mathrm{CuAAC}$ reaction. The $\pi$-conjugated nature of the rhodamine matches well the partly $\pi$-conjugated honeycomb structure of GO. Assembly of 32 and 33 on GO occurs efficiently leading to the glycosheet materials 34-35 respectively [59]. What is very interesting in this system is that rhodamine B plays both the role of the $\pi$-conjugated entity allowing for the stacking/stabilization on GO and the role of the fluorescent group which is the essential feature of this fluorogenic system.

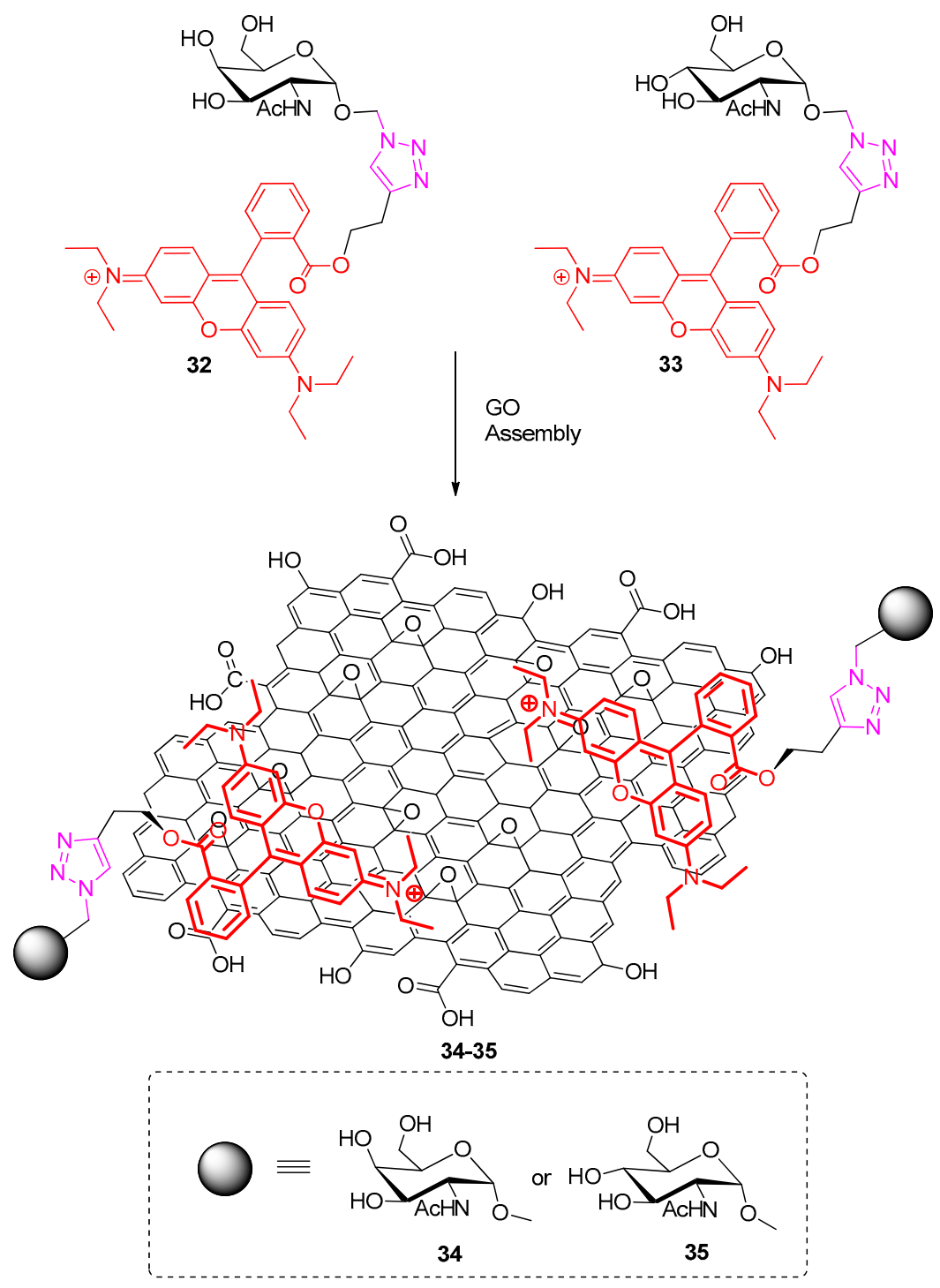

Figure 10. Click chemistry enabled preparation of the 2D glycosheet materials by Zhang et al. [59].

Saccharides tethered on $\pi$-conjugated molecules (e.g., PAHs) through click chemistry can also lead to non-covalent functionalizations of CRMs other than graphene. Assali et al. recently reported on the development of modified MWCNTs with sugar-based amphiphiles tethered on tetrabenzo[a,c,g,i]fluorene (TBF) (see Figure 11) [60]. The $\pi-\pi$ stacking interactions between the aforementioned aromatic entities and the surface of 
MWCNTs enabled the preparation of this interesting composite material involving CNTs and sugar entities. The tethering of the sugars was achieved through an oligo ethylene glycol bridge with a terminal azide which via a CuAAC reaction with alkyne-modified TBF resulted in various sugar amphiphiles (example structure 36). Amphiphiles like 36 efficiently bind the surface of MWCNTs non-covalently through $\pi-\pi$ stacking interactions forming composites similar to 37 (Figure 11). In terms of applications, the as formed aggregates were found to be involved in specific lectin-ligand interactions in an analogous fashion to glycoconjugates on a cell-membrane [60,61].

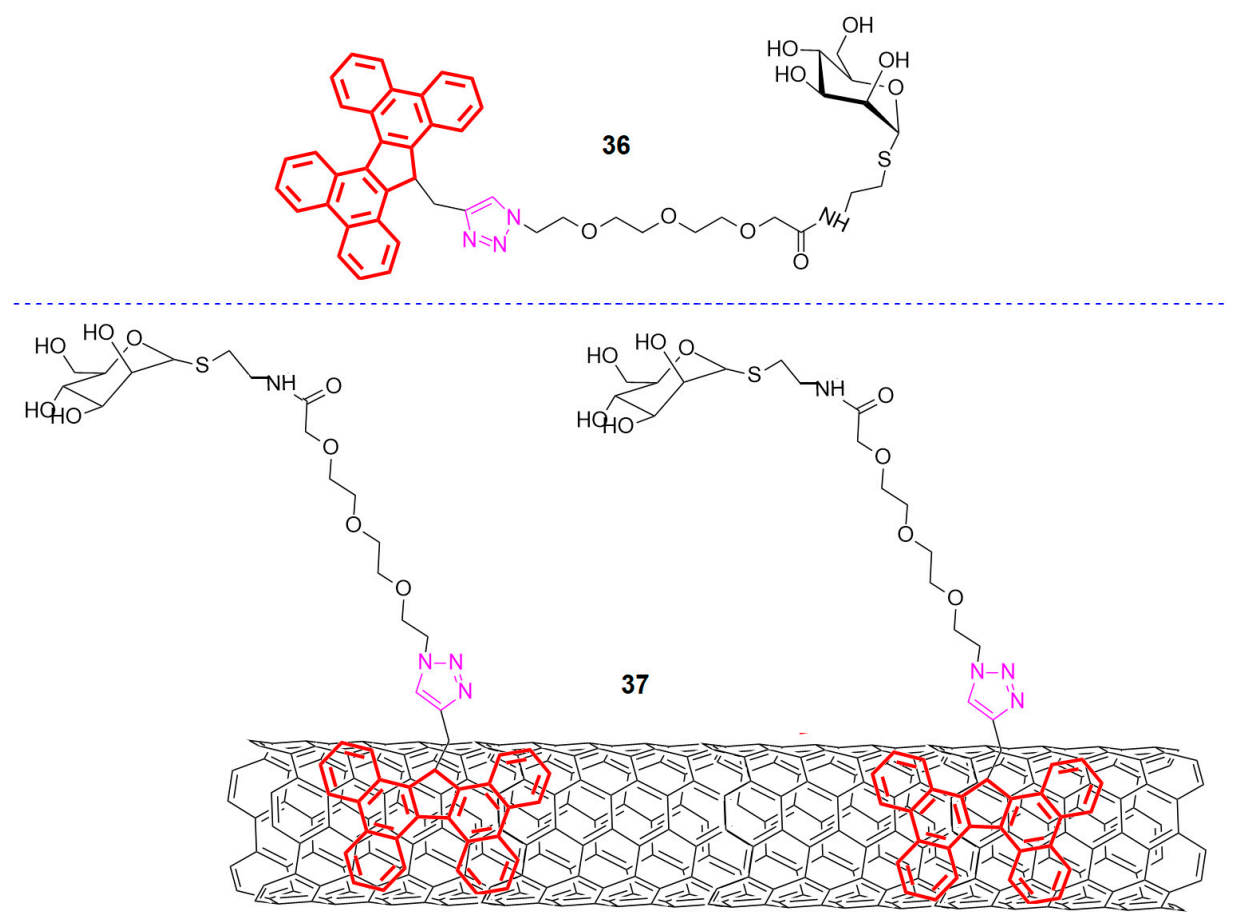

Figure 11. A sugar amphiphile and its aggregate with MWCNTs by Assali et al. [60].

Wu et al. [62], some years earlier, reported on CNTs functionalization with glycodendrimers involving a pyrene tail which exhibits high aptitude to attach non-covalently the surface of CNTs (as well as other CRMs, e.g., graphene). The glycodendrimers were prepared through a click chemistry-assisted methodology leading to triazole repeated binding motifs. This way, pyrene branch-terminating monosaccharides are formed. The glycodendrimers by Wu et al. have been proposed for protective coatings and they are capable to moderate the cytotoxicity of CNTs when bound to their surface [62].

Pyrene among other PAHs is an indispensable part of many non-covalent functionalizations to graphene, CNTs and other CRMs [63-65]. This fact is reflected by the large number of published works in this research field pertaining to GBM functionalization strategies which involve derivatized pyrenes [5,6,63-65]. There is also a significant subgroup of the aforementioned research field involving pyrene sugar-modifications enabled by click chemistry which could lead to interesting composites when combined with graphene or other CRMs. Furthermore, studying such PAH modifications with saccharides constitutes an important step prior to applying covalent functionalization strategies on graphene. Indeed, modelling graphene modifications with the use of variously sized PAHs has been identified as an important research approach $[66,67]$. Some characteristic selected examples of this class of compounds are depicted in Figure 12 [68]. 


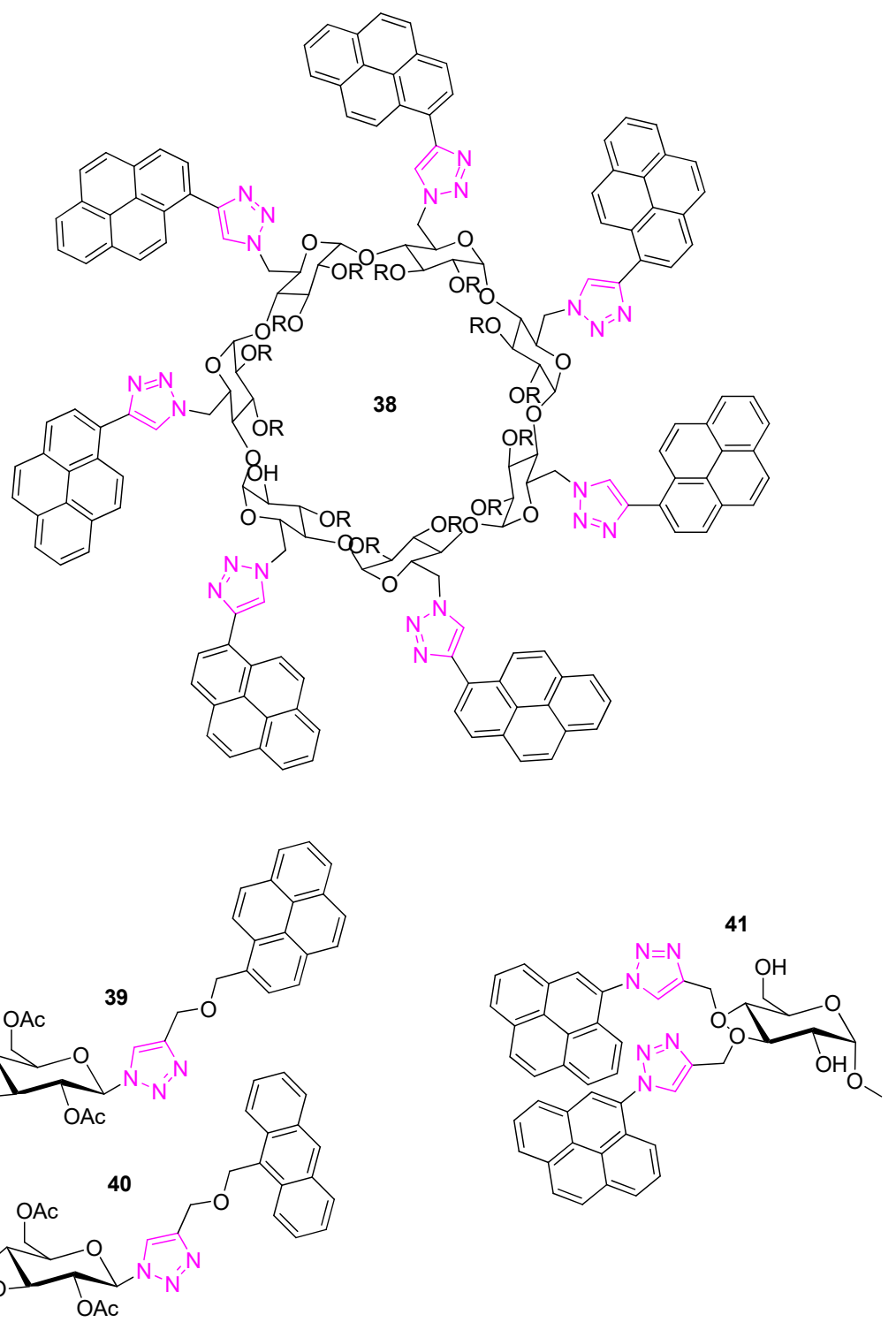

Figure 12. Examples of a saccharide modified pyrene derivatives. A pyrenyl $\beta$-cyclodextrin 38 by He et al. [69], pyrenyl (39) and anthracenyl (40) glucose derivatives by Thakur et al. [70] and glycoprobe by He et al. [71].

\section{Covalent Click Chemistry Approaches Applied to Other CRMs}

In this paragraph, focus is placed on click approaches allowing for covalent functionalization of CRMs other than graphene. One of the most prominent allotropes of carbon which during the last decades has attracted a great deal of interest is CNTs [72]. CNTs constitute a well-studied type of CRMs in terms of their outstanding physicochemical properties. Numerous applications of CNT-involving materials have been proposed to date spanning from optoelectronic to environmental applications [72-76]. One of their important characteristics is their very high aspect ratio (length to diameter ratio can be higher than $10^{6}$ [73]). A vast number of described functionalization methodologies for CNTs is known to date [72]. Yet, a common problem for many applications is the insolubility of CNTs in any organic solvent or water [28,72]. Many attempts have been made towards resolving this problem and click chemistry approaches have demonstrated a great role towards this endeavor $[77,78]$. Click chemistry offers various covalent functionalization possibilities for CNTs [28]. Various oligo- and poly-saccharides have been employed up to date as hydrophilic units which increase the solubility and dispersibility of CNTs in various solvents. In the previous paragraph some examples of non-covalent functionalizations of 
CNTs were reviewed yet, here focus is placed on covalent functionalization approaches as these approaches could lead to soluble CNT-based materials.

Guo et al. [79] reported on the functionalization of CNTs with $\beta-C D$ through a CuAAC methodology using CuI-DBU and DMF as a solvent. (Figure 13A). A first pre-alkynemodification of CNTs was required. This was achieved through a reaction of CNTs with $p$-amino-O-propargylphenol and isoamylnitrite to afford product 42 (Figure 13A). The sidewall alkyne-modified CNTs (42) efficiently reacted with azide-functionalized $\beta$-CD (43) to form $\beta$-CD-CNTs (44). The method described led to a new type of functional material. As an application, the binding ability of the $\beta-\mathrm{CD}-\mathrm{CNT}$ fluorescence spectroscopic study was conducted towards quinine which was found to efficiently enter the $\beta$-CD cavity of 43 [79]. (It is worth mentioning that quinine/ $\beta$-Cyclodextrin constitutes an important modelling system for simulating enzyme-substrate interactions [80]). Notably, this approach is similar to the method employed by Ye et al. [40] (see Figure 6) pertaining to GO yet in the latter case another pre-modification of the CRM was required prior to click.

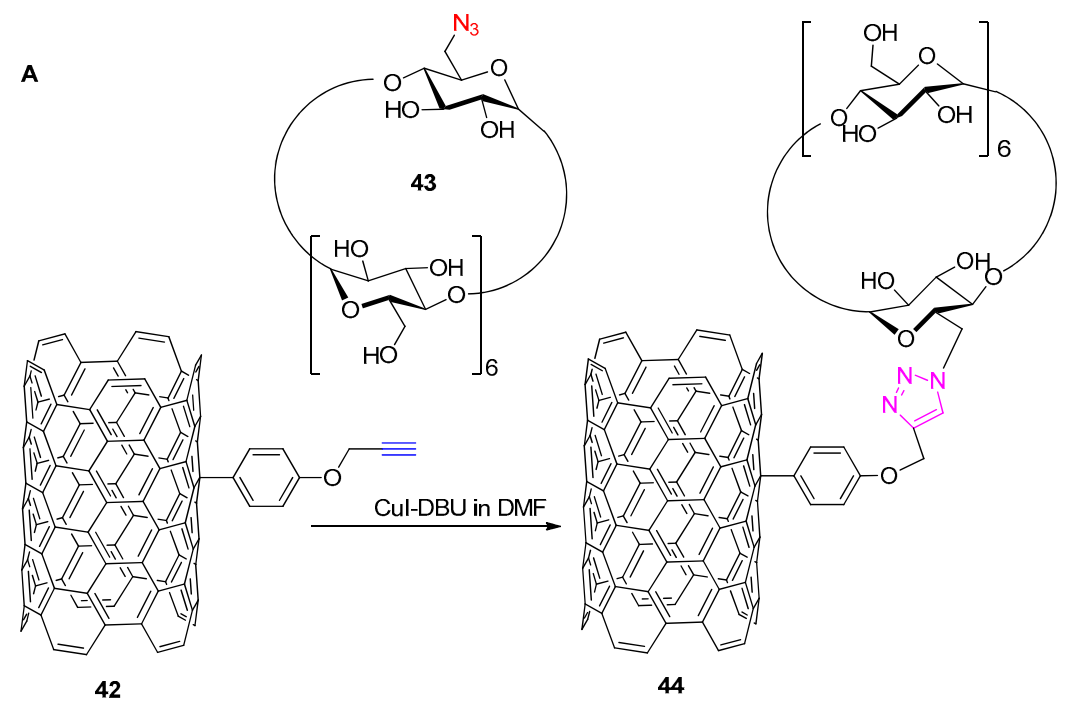

B
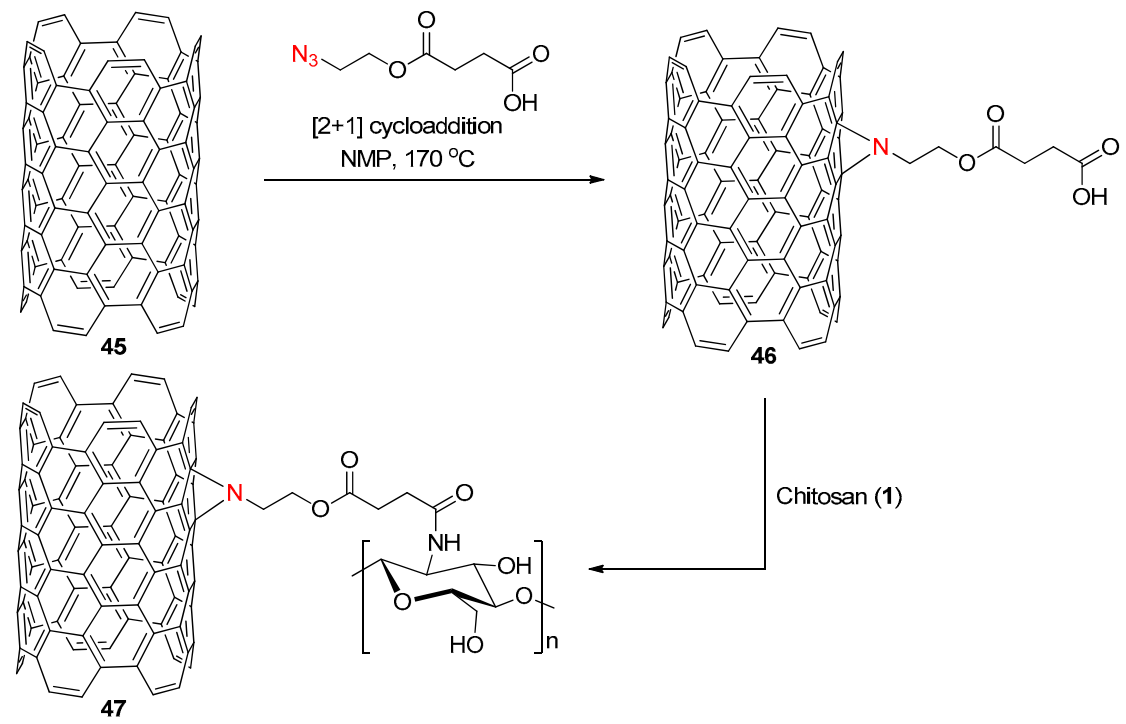

Figure 13. (A) Synthetic procedure used for the coupling of $\beta-C D$ on SWCNTs by Guo et al. [79] and (B) synthetic route followed for the chitosan-functionalization of MWCNTs by Yadav et al. [81]. 
Click strategies other than the CuAAC chemistry allowing for the grafting of CNTinvolving materials with polysaccharides have also been reported. Yadav et al. for example reported on the functionalization of multiwalled carbon nanotubes (MWCNTs 45) with chitosan (1) [81]. The synthetic strategy employed involved a first derivatization (through amidation) of chitosan with a terminal azide (see Figure 13B) which was then directly clicked on the surface of MWCNTs by means of a [2+1] nitrene cycloaddition to afford product 46 . The latter reaction has recently been applied on CNTs [82-84] with success enabling grafting of various functionalities on CNTs. Noteworthy [2+1] nitrene cycloaddition on CNTs leads to derivatives which retain $\pi$-conjugation rendering this method very attractive for applications in optoelectronics.

From a sugar-CNTs-functionalization perspective, what makes the click reaction by Yadav et al. attractive, is the fact that only one derivatization of the polysaccharide with a linker encompassing an azide-terminus is required. The CNTs are then used directly, i.e., without any pre-derivatization. The reaction is brought about at temperatures typically higher than $150{ }^{\circ} \mathrm{C}$ in solvents like N-methyl-2-pyrrolidone (NMP). The reported degree of substitution on MWCNTs in the final product (47) was as high as 1.8 chitosan polymeric chains every 1000 carbon atoms of MWCNTs. When it comes to the properties of the final material it was shown that it exhibits enhanced mechanical properties and antimicrobial activity when compared to the parent materials.

In this paragraph it has been shown that click-chemistry approaches are also suitable for CRM-modifications with sugars (CRMs other than GBMs). The techniques used are the same as described in corresponding graphene modifications. Nonetheless, different pre-modification methods are applied depending on the CRM-substrate.

\section{Future Perspectives}

To the best of the author's knowledge, very few examples on click-sugar modified CRMs other than CNTs and GBMs can be found. There are various examples involving PAHs (for example, see Figure 12 and corresponding discussion) however, the field is open to many more combinations of CRMs and (poly)saccharides. The increasing tendency of annual number of published works pertaining to graphene modifications using click chemistry (see Figure 1) signifies a bright future for this research field which can bring together the world of sugars and that of graphene chemistry. Of particular interest are Diels Alder click-reactions, which are becoming more and more popular. On the other hand, CuAAC click-reactions are very attractive since both azide- and alkyne- modifications of sugars are facile and have been long studied for other purposes (e.g., in bioconjugation).

\section{Conclusions}

This paper provides a review on the recent research pertaining to the modifications of graphene and other CRMs with (poly)saccharides enabled by click chemistry. Emphasis was given to click chemistry approaches which have been shown to allow for either covalently or non-covalently graphene functionalizations. The review expands to CRMs like CNTs and includes a range of examples and potential applications of the (poly)saccharide modified materials. In most cases reviewed, it was shown that (poly)saccharide modifications increased the hydrophilicity and dispersibility of CRMs in water or other solvents. Moreover, the materials thus produced exhibit multifunctional behavior and are proposed as important candidates for various new applications.

Funding: The authors are grateful to ÅForsk Foundation (grant number, 20-280), Formas (grant number, 2019-01583), STINT (grant number, IB2020-8594) and I Bergh scholarship. Qilu young scholar program of Shandong University is also acknowledged for the financial support.

Acknowledgments: The authors would like to thank Dimitris Matiadis (NCSR Demokritos, Athens, Greece) for stimulating discussions on the functionalization of graphene with biocompatible compounds/polymers.

Conflicts of Interest: The authors declare no conflict of interest. 


$\begin{array}{ll}\begin{array}{l}\text { Abbreviations } \\ \text { AFM }\end{array} & \text { Atomic Force Microscopy } \\ \text { CD } & \text { cyclodextrin } \\ \text { CNTs } & \text { Carbon Nanotubes } \\ \text { CRMs } & \text { Carbon Rich Materials } \\ \text { GO } & \text { Graphene Oxide } \\ \text { rGO } & \text { reduced Graphene Oxide } \\ \text { GBM } & \text { Graphene-Based Material } \\ \text { MWCNTs } & \text { Multi Walled Carbon Nanotubes } \\ \text { PSs } & \text { Polysaccharides }\end{array}$

\section{References}

1. Slaven, G.; Hubbard, W.J.; Reina, A.; Kong, J.; Branton, D.; Golovchenko, J.A. Graphene as a subnanometre trans-electrode membrane. Nat. Cell Biol. 2010, 467, 190-193. [CrossRef]

2. Xu, S.; Zhan, J.; Man, B.; Jiang, S.; Yue, W.; Gao, S.; Guo, C.; Liu, H.; Li, Z.; Wang, J.; et al. Real-time reliable determination of binding kinetics of DNA hybridization using a multi-channel graphene biosensor. Nat. Commun. 2017, 8, 14902. [CrossRef] [PubMed]

3. Konkena, B.; Vasudevan, S. Understanding Aqueous Dispersibility of Graphene Oxide and Reduced Graphene Oxide through pKa Measurements. J. Phys. Chem. Lett. 2012, 3, 867-872. [CrossRef]

4. Eda, G.; Chhowalla, M. Chemically Derived Graphene Oxide: Towards Large-Area Thin-Film Electronics and Optoelectronics. Adv. Mater. 2010, 22, 2392-2415. [CrossRef]

5. Georgakilas, V. (Ed.) Functionalization of Graphene; Wiley-VCH Verlag GmbH \& Co. KGaA: Weinheim, Germany, 2014; ISBN 9783527672790.

6. Georgakilas, V.; Otyepka, M.; Bourlinos, A.B.; Chandra, V.; Kim, N.; Kemp, K.C.; Hobza, P.; Zboril, R.; Kim, K.S. Functionalization of Graphene: Covalent and Non-Covalent Approaches, Derivatives and Applications. Chem. Rev. 2012, 112, 6156-6214. [CrossRef]

7. Khan, A.; Jawaid, M.; Neppolian, B.; Asiri, A.M. (Eds.) Graphene Functionalization Strategies; Carbon Nanostructures; Springer: Singapore, 2019; ISBN 978-981-32-9056-3.

8. Kim, H.W.; Yoon, H.W.; Yoon, S.-M.; Yoo, B.M.; Ahn, B.K.; Cho, Y.H.; Shin, H.J.; Yang, H.; Paik, U.; Kwon, S.; et al. Selective Gas Transport Through Few-Layered Graphene and Graphene Oxide Membranes. Science 2013, 342, 91-95. [CrossRef]

9. Papadakis, R.; Li, H.; Bergman, J.; Lundstedt, A.; Jorner, K.; Ayub, R.; Haldar, S.; Jahn, B.O.; Denisova, A.; Zietz, B.; et al. Metal-free photochemical silylations and transfer hydrogenations of benzenoid hydrocarbons and graphene. Nat. Commun. 2016, 7, 12962. [CrossRef]

10. Lundstedt, A.; Papadakis, R.; Li, H.; Han, Y.; Jorner, K.; Bergman, J.; Leifer, K.; Grennberg, H.; Ottosson, H. White-Light Photoassisted Covalent Functionalization of Graphene Using 2-Propanol. Small Methods 2017, 1, 1700214. [CrossRef]

11. Kansara, V.; Patil, R.; Tripathi, R.; Jha, P.K.; Bahadur, P.; Tiwari, S. Functionalized graphene nanosheets with improved dispersion stability and superior paclitaxel loading capacity. Colloids Surf. B 2019, 173, 421-428. [CrossRef]

12. Li, H.; Papadakis, R.; Jafri, S.; Thersleff, T.; Michler, J.; Ottosson, H.; Leifer, K. Superior adhesion of graphene nanoscrolls. Commun. Phys. 2018, 1, 44. [CrossRef]

13. Kirschning, A.; Dibbert, N.; Dräger, G. Chemical Functionalization of Polysaccharides-Towards Biocompatible Hydrogels for Biomedical Applications. Chem.-A Eur. J. 2018, 24, 1231-1240. [CrossRef] [PubMed]

14. Cadinoiu, A.N.; Rata, D.M.; Atanase, L.I. Biocompatible injectable polysaccharide materials for drug delivery. In Polysaccharide Carriers for Drug Delivery; Elsevier BV: Geneva, Switzerland, 2019; pp. 127-154.

15. Huang, H.; Su, S.; Wu, N.; Wan, H.; Wan, S.; Bi, H.; Sun, L. Graphene-Based Sensors for Human Health Monitoring. Front. Chem. 2019, 7, 399. [CrossRef] [PubMed]

16. Pumera, M. Graphene in biosensing. Mater. Today 2011, 14, 308-315. [CrossRef]

17. Liu, H.; Li, T.; Liu, Y.; Qin, G.; Wang, X.; Chen, T. Glucose-Reduced Graphene Oxide with Excellent Biocompatibility and Photothermal Efficiency as well as Drug Loading. Nanoscale Res. Lett. 2016, 11, 211. [CrossRef] [PubMed]

18. Han, Y.; Li, H.; Jafri, S.H.M.; Ossipov, D.; Hilborn, J.; Leifer, K. Optimization and analysis of pyrene-maltose functionalized graphene surfaces for Con A detection. Appl. Surf. Sci. 2020, 510, 145409. [CrossRef]

19. Yang, Q.; Pan, X.; Clarke, K.; Li, K. Covalent Functionalization of Graphene with Polysaccharides. Ind. Eng. Chem. Res. 2011, 51, 310-317. [CrossRef]

20. Layek, R.K.; Nandi, A.K. A review on synthesis and properties of polymer functionalized graphene. Polymers 2013, 54, 5087-5103. [CrossRef]

21. Jimenez-Cervantes, E.; López-Barroso, J.; Martínez-Hernández, A.L.; Velasco-Santos, C. Graphene-Based Materials Functionalization with Natural Polymeric Biomolecules. In Recent Advances in Graphene Research; IntechOpen: London, UK, 2016.

22. Makvandi, P.; Ghomi, M.; Ashrafizadeh, M.; Tafazoli, A.; Agarwal, T.; Delfi, M.; Akhtari, J.; Zare, E.N.; Padil, V.V.; Zarrabi, A.; et al. A review on advances in graphene-derivative/polysaccharide bionanocomposites: Therapeutics, pharmacogenomics and toxicity. Carbohydr. Polym. 2020, 250, 116952. [CrossRef] 
23. Castelaín, M.; Martínez, G.; Marco, C.; Ellis, G.J.; Salavagione, H.J. Effect of Click-Chemistry Approaches for Graphene Modification on the Electrical, Thermal, and Mechanical Properties of Polyethylene/Graphene Nanocomposites. Macromolecules 2013, 46, 8980-8987. [CrossRef]

24. Lai, C.; Sun, Y.; Yang, H.; Zhang, X.; Lin, B. The Functionalization of Graphene and Graphene Oxide via Click Chemistry. Acta Chim. Sin. 2013, 71, 901-1224. [CrossRef]

25. Luong, N.D.; Sinh, L.H.; Johansson, L.-S.; Campell, J.; Seppälä, J. Functional Graphene by Thiol-ene Click Chemistry. Chem. - $A$ Eur. J. 2015, 21, 3183-3186. [CrossRef]

26. Yáñez-Sedeño, P.; González-Cortés, A.; Campuzano, S.; Pingarrón, J.M. Copper(I)-Catalyzed Click Chemistry as a Tool for the Functionalization of Nanomaterials and the Preparation of Electrochemical (Bio)Sensors. Sensors 2019, 19, 2379. [CrossRef] [PubMed]

27. Haley, M.M.; Tykwinski, R.R. (Eds.) Carbon-Rich Compounds; Wiley: Hoboken, NJ, USA, 2006; ISBN 9783527312245.

28. Click Chemistry for Biotechnology and Materials Science. In Click Chemistry for Biotechnology and Materials Science; Wiley: Hoboken, NJ, USA, 2009.

29. Rostovtsev, V.V.; Green, L.G.; Fokin, V.V.; Sharpless, K.B. A Stepwise Huisgen Cycloaddition Process: Copper(I)-Catalyzed Regioselective "Ligation" of Azides and Terminal Alkynes. Angew. Chem. Int. Ed. 2002, 41, 2596-2599. [CrossRef]

30. Dreyer, D.R.; Park, S.; Bielawski, C.W.; Ruoff, R.S. The chemistry of graphene oxide. Chem. Soc. Rev. 2010, 39, 228-240. [CrossRef]

31. Georgakilas, V.; Tiwari, J.N.; Kemp, K.C.; Perman, J.; Bourlinos, A.B.; Kim, K.S.; Zboril, R. Noncovalent Functionalization of Graphene and Graphene Oxide for Energy Materials, Biosensing, Catalytic, and Biomedical Applications. Chem. Rev. 2016, 116, 5464-5519. [CrossRef]

32. De Alvarenga, E.S. Characterization and Properties of Chitosan, Biotechnology of Biopolymers; Elnashar, M., Ed.; IntechOpen: London, UK, 2011. [CrossRef]

33. Lalov, I. Treatment of waste water from distilleries with chitosan. Water Res. 2000, 34, 1503-1506. [CrossRef]

34. Zhang, H.; Li, Y.; Shi, R.; Chen, L.; Fan, M. A robust salt-tolerant superoleophobic chitosan/nanofibrillated cellulose aerogel for highly efficient oil/water separation. Carbohydr. Polym. 2018, 200, 611-615. [CrossRef]

35. Zhang, Y.; Zhang, M. Synthesis and characterization of macroporous chitosan/calcium phosphate composite scaffolds for tissue engineering. J. Biomed. Mater. Res. 2001, 55, 304-312. [CrossRef]

36. Hsan, N.; Dutta, P.K.; Kumar, S.; Bera, R.; Das, N. Chitosan grafted graphene oxide aerogel: Synthesis, characterization and carbon dioxide capture study. Int. J. Biol. Macromol. 2019, 125, 300-306. [CrossRef]

37. Ryu, H.J.; Mahapatra, S.S.; Yadav, S.K.; Cho, J.W. Synthesis of click-coupled graphene sheet with chitosan: Effective exfoliation and enhanced properties of their nanocomposites. Eur. Polym. J. 2013, 49, 2627-2634. [CrossRef]

38. Kabiri, R.; Namazi, H. Surface grafting of reduced graphene oxide using nanocrystalline cellulose via click reaction. J. Nanopart. Res. 2014, 16, 2474. [CrossRef]

39. Wong, C.-H.; Zimmerman, S.C. Orthogonality in organic, polymer, and supramolecular chemistry: From Merrifield to click chemistry. Chem. Commun. 2013, 49, 1679-1695. [CrossRef]

40. Ye, Y.; Mao, X.; Xu, J.; Kong, J.; Hu, X. Functional Graphene Oxide Nanocarriers for Drug Delivery. Int. J. Polym. Sci. 2019, 2019, 8453493. [CrossRef]

41. Fakayode, S.O.; Lowry, M.; Fletcher, K.A.; Huang, X.; Powe, A.M.; Warner, I.M. Cyclodextrins Host- Guest Chemistry in Analytical and Environmental Chemistry. Curr. Anal. Chem. 2007, 3, 171-181. [CrossRef]

42. Harada, A.; Takashima, Y.; Yamaguchi, H. Cyclodextrin-based supramolecular polymers. Chem. Soc. Rev. 2009, 38, 875-882. [CrossRef] [PubMed]

43. Del Valle, E.M.M. Cyclodextrins and their uses: A review. Process. Biochem. 2004, 39, 1033-1046. [CrossRef]

44. Otero-Espinar, F.; Torres-Labandeira, J.; Alvarez-Lorenzo, C.; Blanco-Méndez, J. Cyclodextrins in drug delivery systems. J. Drug Deliv. Sci. Technol. 2010, 20, 289-301. [CrossRef]

45. Park, K.D.; Lee, Y.; Ryu, S.B.; Sung, H.-J.; Park, K.D. Oxidized cyclodextrin-functionalized injectable gelatin hydrogels as a new platform for tissue-adhesive hydrophobic drug delivery. RSC Adv. 2017, 7, 34053-34062. [CrossRef]

46. Tasdelen, M.A. Diels-Alder "click" reactions: Recent applications in polymer and material science. Polym. Chem. 2011, 2, 2133-2145. [CrossRef]

47. Gacal, B.; Durmaz, H.; Tasdelen, M.A.; Hizal, G.; Tunca, U.; Yagci, Y.; Demirel, A.L. Anthracene-Maleimide-Based Diels-Alder "Click Chemistry" as a Novel Route to Graft Copolymers. Macromolecules 2006, 39, 5330-5336. [CrossRef]

48. Zhang, X.; Cong, Y.; Zhang, B. Reduced graphene oxide/liquid crystalline oligomer composites based on reversible covalent chemistry. Phys. Chem. Chem. Phys. 2017, 19, 6082-6089. [CrossRef]

49. Munirasu, S.; Albuerne, J.; Boschetti-De-Fierro, A.; Abetz, V. Functionalization of Carbon Materials using the Diels-Alder Reaction. Macromol. Rapid Commun. 2010, 31, 574-579. [CrossRef]

50. Huang, J.; Yin, Z.; Wu, J. Covalent attachment of chitosan to graphene via click chemistry for superior antibacterial activity. Mater. Adv. 2020, 1, 579-583. [CrossRef]

51. Liu, J.; Wang, R.; Cui, L.; Tang, J.; Liu, Z.; Kong, Q.; Yang, W.; Gooding, J.; Gooding, J.J. Using Molecular Level Modification to Tune the Conductivity of Graphene Papers. J. Phys. Chem. C 2012, 116, 17939-17946. [CrossRef]

52. Zhu, Y.; James, D.K.; Tour, J.M. New Routes to Graphene, Graphene Oxide and Their Related Applications. Adv. Mater. 2012, 24, 4924-4955. [CrossRef] 
53. Golosova, A.A.; Papadakis, C.M.; Jordan, R. Chemical functionalization of carbon nanotubes with aryl diazonium salts. MRS Proc. 2011, 1362, 1114-1120. [CrossRef]

54. Namvari, M.; Namazi, H. Sweet graphene I: Toward hydrophilic graphene nanosheets via click grafting alkyne-saccharides onto azide-functionalized graphene oxide. Carbohydr. Res. 2014, 396, 1-8. [CrossRef]

55. Tornoe, C.; Christensen, C.; Meldal, M. Peptidotriazoles on Solid Phase: [1,2,3]-Triazoles by Regiospecific Copper(I)-Catalyzed 1,3-Dipolar Cycloadditions of Terminal Alkynes to Azides. J. Org. Chem. 2002, 67, 3057-3064. [CrossRef]

56. Namazi, H.; Namazi, H. Preparation of efficient magnetic biosorbents by clicking carbohydrates onto graphene oxide. J. Mater. Sci. 2015, 50, 5348-5361. [CrossRef]

57. Speranza, M. The Role of Functionalization in the Applications of Carbon Materials: An Overview. C-J. Carbon Res. 2019, 5, 84 [CrossRef]

58. Kaminska, I.; Barras, A.; Coffinier, Y.; Lisowski, W.; Roy, S.; Niedziolka-Jonsson, J.; Woisel, P.; Lyskawa, J.; Opallo, M.; Siriwardena, A.; et al. Preparation of a Responsive Carbohydrate-Coated Biointerface Based on Graphene/Azido-Terminated Tetrathiafulvalene Nanohybrid Material. ACS Appl. Mater. Interfaces 2012, 4, 5386-5393. [CrossRef] [PubMed]

59. Zhang, H.-L.; Wei, X.-L.; Zang, Y.; Cao, J.-Y.; Liu, S.; He, X.-P.; Chen, Q.; Long, Y.-T.; Li, J.; Chen, G.-R.; et al. Fluorogenic Probing of Specific Recognitions between Sugar Ligands and Glycoprotein Receptors on Cancer Cells by an Economic Graphene Nanocomposite. Adv. Mater. 2013, 25, 4097-4101. [CrossRef] [PubMed]

60. Assali, M.; Leal, M.P.; Fernández, I.; Romero-Gomez, P.; Baati, R.; Khiar, N. Improved non-covalent biofunctionalization of multi-walled carbon nanotubes using carbohydrate amphiphiles with a butterfly-like polyaromatic tail. Nano Res. 2010, 3, 764-778. [CrossRef]

61. Gingras, M.; Chabre, Y.M.; Roy, M.; Roy, R. How do multivalent glycodendrimers benefit from sulfur chemistry? Chem. Soc. Rev. 2013, 42, 4823-4841. [CrossRef]

62. Wu, P.; Chen, X.; Hu, N.; Tam, U.C.; Blixt, O.; Zettl, A.; Bertozzi, C.R. Biocompatible Carbon Nanotubes Generated by Functionalization with Glycodendrimers. Angew. Chem. Int. Ed. 2008, 47, 5022-5025. [CrossRef]

63. Ji, X.; Cuib, L.; Xu, Y.; Liu, J. Non-covalent interactions for synthesis of new graphene based composites. Compos. Sci. Technol. 2015, 106, 25-31. [CrossRef]

64. Tuncel, D. Non-covalent interactions between carbon nanotubes and conjugated polymers. Nanoscale 2011, 3, 3545-3554. [CrossRef]

65. Liu, J.; Tang, J.; Gooding, J.J. Strategies for chemical modification of graphene and applications of chemically modified graphene. J. Mater. Chem. 2012, 22, 12435-12452. [CrossRef]

66. Pykal, M.; Jurečka, P.; Karlický, F.; Otyepka, M. Modelling of graphene functionalization. Phys. Chem. Chem. Phys. 2016, 18, 6351-6372. [CrossRef]

67. Lundstedt, A. Development of Mild Methods for Selective Covalent Functionalization of Graphene. Ph.D. Thesis, Uppsala University, Stockholm, Sweden, 2017.

68. He, X.-P.; Zang, Y.; James, T.D.; Li, J.; Chen, D.; Xie, J. Fluorescent glycoprobes: A sweet addition for improved sensing. Chem. Commun. 2017, 53, 82-90. [CrossRef]

69. He, X.-P.; Li, R.-H.; Maisonneuve, S.; Ruan, Y.; Chen, G.-R.; Xie, J. Fluorogenic supramolecular complexes formed between pyrenyl- $\beta$-cyclodextrin and glyco-rhodamine for the selective detection of lectins. Chem. Commun. 2014, 50, 14141-14144. [CrossRef] [PubMed]

70. Thakur, A.; Mandal, D.; Deb, P.; Mondal, B.; Ghosh, S. Synthesis of triazole linked fluorescent amino acid and carbohydrate bio-conjugates: A highly sensitive and skeleton selective multi-responsive chemosensor for $\mathrm{Cu}(\mathrm{ii})$ and $\mathrm{Pb}(\mathrm{ii}) / \mathrm{Hg}$ (ii) ions. $R S C$ Adv. 2014, 4, 1918-1928. [CrossRef]

71. He, X.; Xie, J.; Chen, G.-R.; Chen, K. Pyrene Excimer-based Bis-triazolyl Pyranoglycoligands as Specific Mercury Sensors. Chin. J. Chem. 2012, 30, 2874-2878. [CrossRef]

72. Guldi, D.M.; Martín, N. (Eds.) Carbon Nanotubes and Related Structures. Synthesis, Characterization, Functionalization, and Applications; Wiley-VCH Verlag GmbH \& Co. KGaA: Weinheim, Germany, 2010.

73. Gupta, N.; Gupta, S.M.; Sharma, S.K. Carbon nanotubes: Synthesis, properties and engineering applications. Carbon Lett. 2019, 29, 419-447. [CrossRef]

74. Ibrahim, K.S. Carbon nanotubes-properties and applications: A review. Carbon Lett. 2013, 14, 131-144. [CrossRef]

75. Park, S.; Vosguerichian, M.; Bao, Z. A review of fabrication and applications of carbon nanotube film-based flexible electronics. Nanoscale 2013, 5, 1727-1752. [CrossRef]

76. Yang, H.Y.; Han, Z.J.; Yu, S.F.; Pey, K.L.; Ostrikov, K.; Karnik, R. Carbon nanotube membranes with ultrahigh specific adsorption capacity for water desalination and purification. Nat. Commun. 2013, 4, 2220. [CrossRef]

77. Li, H.; Cheng, F.; Duft, A.M.; Adronov, A. Functionalization of Single-Walled Carbon Nanotubes with Well-Defined Polystyrene by "Click" Coupling. J. Am. Chem. Soc. 2005, 127, 14518-14524. [CrossRef]

78. Li, H.; Adronov, A. Water-soluble SWCNTs from sulfonation of nanotube-bound polystyrene. Carbon 2007, 45, 984-990. [CrossRef]

79. Guo, Z.; Liang, L.; Liang, J.-J.; Ma, Y.-F.; Yang, X.-Y.; Ren, D.-M.; Chen, Y.-S.; Zheng, J.-Y. Covalently $\beta$-cyclodextrin modified single-walled carbon nanotubes: A novel artificial receptor synthesized by 'click' chemistry. J. Nanopart. Res. 2008, 10, 1077-1083. [CrossRef] 
80. Fan, Z.; Diao, C.-H.; Song, H.-B.; Jing, Z.-L.; Yu, M.; Chen, X.; Guo, M.-J. Encapsulation of Quinine by $\beta$-Cyclodextrin: Excellent Model for Mimicking Enzyme-Substrate Interactions. J. Org. Chem. 2006, 71, 1244-1246. [CrossRef] [PubMed]

81. Yadav, S.K.; Mahapatra, S.S.; Yadav, M.K.; Dutta, P.K. Mechanically robust biocomposite films of chitosan grafted carbon nanotubes via the [2+1] cycloaddition of nitrenes. RSC Adv. 2013, 3, 23631. [CrossRef]

82. Balasubramanian, K.; Burghard, M. Chemically Functionalized Carbon Nanotubes. Small 2005, 1, 180-192. [CrossRef] [PubMed]

83. Gao, C.; He, H.; Zhou, L.; Zheng, X.; Zhang, Y. Scalable Functional Group Engineering of Carbon Nanotubes by Improved One-Step Nitrene Chemistry. Chem. Mater. 2009, 21, 360-370. [CrossRef]

84. Setaro, A.; Adeli, M.; Glaeske, M.; Przyrembel, D.; Bisswanger, T.; Gordeev, G.; Maschietto, F.; Faghani, A.; Paulus, B.; Weinelt, M.; et al. Preserving $\pi$-conjugation in covalently functionalized carbon nanotubes for optoelectronic applications. Nat. Commun. 2017, 8, 14281. [CrossRef] 